\title{
Estimation of Road Traffic Mortality in Kurdistan Province, Iran, During 2004-2009, Using Capture-Recapture Method

\author{
Lida Gorgin $^{1 *}$, Shaker Salarilak ${ }^{2}$, Davood Khorasani-Zavareh ${ }^{3}$
}

1. Department of Epidemiology, School of Medicine, Urmia University of Medical Sciences, Urmia, Iran.

2. Department of Epidemiology, Tabriz Branch, Islamic Azad University, Tabriz, Iran.

3. Department of Health in Disaster and Emergency, School of Health, Safety and Environment, Shahid Beheshti University of Medical Sciences, Tehran, Iran.

Crtation: Gorgin L, Salarilak Sh, Khorasani-Zavareh D. Estimation of road traffic mortality in Kurdistan province, Iran, during 2004-2009, using capture-recapture method. Health in Emergencies and Disasters Quarterly. 2016; 1(3):147-154. http://doi.org/10.15412/j.hdq.09010305

d. $]^{\text {: }}$ : http://doi.org/10.15412/j.hdq.09010305

Article info:

Received: 22 Oct. 2015

Accepted: 09 Feb. 2016

\section{Keywords:}

Capture-recapture, Traffic accidents, Mortality, Iran

\section{ABSTRACT}

Background: To reduce traffic injuries in the country, health professionals should have accurate estimates of road traffic deaths. Multiple and sometimes inconsistent statistics presented by organizations in charge create high degree of uncertainty for planners and decision makers. To achieve an accurate estimate, several methods are available. Of them, capture-recapture method seems to be an appropriate and affordable method regarding the reliability of the data sources. This study aimed to estimate the number of road traffic deaths in Kurdistan Province during 2004-2009, using capture-recapture method and based on 2 sources of data obtained from Death Registration System and Forensic Medicine Department.

Materials and Methods: All deaths due to road traffic accidents in Kurdistan Province were extracted during 2004-2009. These deaths were legally registered in Death Registration System and Forensic Medicine Department. Shared cases among these 2 sources were identified based on full name, age, gender, and date of death and finally the accurate number of deaths was calculated using the correct volume formula.

Results: During study period, Forensic Medicine Department of the province had registered about 3289 cases of road traffic mortalities and Death Registration System had registered 3771 cases of death resulting from road traffic accidents. Using capture-recapture method, the number of deaths in the same years was estimated as 5726 people (5818-5634:CI95\%). The proportion of mortality registered in the Death Registration System and Forensic Medicine Department of the province to the total estimated deaths were $65.8 \%$ and $57.4 \%$, respectively and both systems together covered $85.4 \%$ of road traffic deaths, i.e. under-reporting of about 832 people.

Conclusion: The results of the present study indicate that none of 2 sources of Forensic Medicine Department and Death Registration System, per se or both, fully covered road traffic mortalities and using capture-recapture method can help estimate the actual number of deaths.

\footnotetext{
* Corresponding Author:

Lida Gorgin, MSc.

Address: Department of Epidemiology, Faculty of Medicine, Urmia University of Medical Sciences, Urmia, Iran.

E-mail: gorgin.lida@yahoo.com
} 


\section{Introduction}

raffic injuries are a major problem in both developing and developed countries [1] $\mathbf{T}$ and can happen for any individual regardless of age, gender, region, and level of income [2]. In 1990, casualties resulting from traffic injuries ranked in the $9^{\text {th }}$ place and it may rise to the $3^{\text {rd }}$ place by 2020 [3]. Statistics show that in low -and middle- income countries, $85 \%$ of deaths and $90 \%$ of lost life years are due to these injuries [4]. Moreover, the World Health Organization reports that in the eastern Mediterranean region, average mortality rate from traffic injuries is 26.4 per 100000 people [5]. Among the most important causes of unintentional injuries are road traffic accidents, which also threatens the public health in Iran [6]. Statistics presented in Iran indicate that the average annual number of traffic injuries increased approximately $19 \%$ from 2001 to 2004 [7] and based on statistics of 2002, 1314098 years of life was lost due to road traffic injuries, exceeding 42 per 100,000 of the population in 2003 [8].

\section{Literature review}

Through using capture-recapture method and data obtained from 2 sources of Police Department and Private Emergency Centers, in a study to estimate mortality caused by traffic injuries in Karachi, Pakistan, Razzak et al. found that the Police registered 544 deaths, while Private emergencies recorded 343 road traffic deaths. However, at least 972 mortalities (1031912:CI95\%) were estimated during the study period by using capture-recapture method. Therefore, only $56 \%$ of trauma mortalities in traffic accidents were recorded by these 2 sources [9].

In Motvalian et al. study (2009) in Kerman, Iran, using capture-recapture method and data from 3 sources of Police Department, Forensic Medicine Department, and hospitals, non-repetitive 471 deaths from traffic accidents were identified from these 3 sources. Using capture-recapture method, they estimated the number of mortalities in this city as 596 people (543-686:C195\%). Therefore, the estimated proportions of the traffic injuries recorded in the Police Department, Forensic Medicine Department, and hospitals to the total deaths were $16 \%, 58 \%$, and $48 \%$, respectively. In general, the shared reported cases included $79 \%$ of the total cases [10].

In 2009, Khorasani et al. conducted a study in West Azerbaijan Province by using capture-recapture method and 2 sources of Death Registration System and Foren- sic Medicine Department. They found that the Death Registration System has recorded 669 cases of death and the Forensic Medicine Department has recorded 665 road traffic deaths. Then, using capture-recapture, the correct number of deaths was estimated as 1018. It was clear that each source has registered $65 \%$ of cases and in general, both sources have registered $87 \%$ of road traffic mortalities, i.e. under-reporting of 121 cases [11].

In 2007, to reduce traffic injuries in the country, important policies have been adopted. To observe these policies, decision makers and health professionals should have access to accurate statistics and mortality rates due to road traffic accidents. The current estimated number of road traffic deaths is not accurate due to limitations in the system of collecting and analysis of events, nonreporting, and differences in the interpretation of information [5].

To obtain detailed statistics, the following methods are available: census, cluster sampling, and registration systems. Since the census and cluster sampling methods are time-consuming and costly and registration systems always have problem of under-reporting, capture-recapture method seems to be a more affordable method to solve the above problems $[12,13]$.

The current study was conducted with the aim of accurate estimation of road traffic deaths by comparing the data recorded from 2 sources of registration system in Kurdistan Province (Death Registration System and Forensic Medicine Department) during 2004 to 2009, using capture-recapture method.

\section{Kurdistan province}

Kurdistan Province has an area of $29000 \mathrm{~km}^{2}$, occupying $\%$ of the country land. It is located in the west of Iran and limited to West Azarbaijan and Zanjan provinces in the north, to Kermanshah Province in the south, to Hamedan and Zanjan in the east, and to Iraq in the east. The province has 10 cities, 25 towns, 27 sections, and 84 rural districts. Bane, Bijar, Saghez, Sanandaj, Divandarreh, Kamyar, Qorveh, Marivan, Sarvabad, and Dehgolan are the most important cities of the province. It is one of Iran's Kurdish provinces in the west. According to the provincial average daily temperature, mid-May to midOctober are the best times to attract tourists. The average temperature during this period is $22^{\circ} \mathrm{C}$ to $28^{\circ} \mathrm{C}$. Due to cold and freezing weather, specific geographical conditions, and high-altitude of the province, the main atmospheric precipitation in winter is snow. 


\section{Materials and Methods}

\section{Capture-recapture method}

This method was initially used to estimate animal populations. During the past decades, it has been used in human societies to estimate the prevalence of illnesses and injuries, including diabetes [14], some cancers [15, 16], AIDS [17], and traffic injuries [18, 19]. Credit of the capture-recapture method depends on the following assumptions that:

- Data sources are independent of each other,

- All members of the population have an equal probability to be registered,

- Variables such as full name, age, gender, and other key and relevant variables are synchronized, and the studied population is closed, i.e., during the study period no major change happens in the direction of migration inside and outside [12].

\section{Forensic medicine department}

To this system, all mortalities from traffic injuries are reported for investigating, registering, and issuing death certificates. The recorded data include full name, gender, age, cause of death, type of road users, type of vehicle, location of incident, place of death, date of accident, date of death, and final reason of death. The data are reported to Forensic Medicine Department by traffic police, visiting relatives of the deceased, Department of Transportation, and hospitals. Registration of death is based on the occurrence of death in the geographical area of Kurdistan.

\section{Death registration system}

It is the other information source for road traffic mortalities, which external causes of death in this system is adapted with ICD10. Collected data include full name, gender, age, date of death, place of death, location of death registration, and address of the deceased. The data are collected and then are registered using different sources, including health centers in the villages, hospitals, civil registration office, and cemeteries in the city [11]. The registration of death is based on the deceased's place of residence in the province.

For this study, all road traffic mortalities recorded during 2004-2009 were studied in Death Registration System, Health Deputy Center, and Forensic Medicine system in Kurdistan Province.
About 3771 cases of deaths in the Death Registration System and 3289 mortalities were recorded in the Forensic Medicine system. For adapting data in Death Registration System and Forensic Medicine Department, they were integrated in Microsoft Access and finally all data were imported in Microsoft Excel for purification and standardization. In Microsoft Excel, full names of individuals were separated and then were reviewed. Names that were registered in different states were identified and matched, and additional prefixes and suffixes were excluded. Then, after homogenizing the format of dates of death, study data were analyzed using SPSS software version 16 . To find out shared cases among the 2 systems, 4 characteristics of individuals, including full name, age, gender, and date of death were considered. Using the identifying dual cases command, those cases with the same 4 properties or similar full name and gender, but different date of death and age less than a year were identified as the shared cases. Finally, using the correct size formula, variance and confidence intervals were claculated (Figure 1)

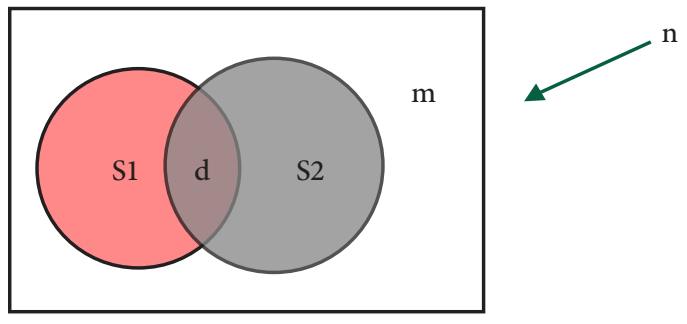

S1=Road traffic mortalities registered in the Death Registration System.

S2=Road traffic mortalities recorded in the Forensic Medicine Department.

$\mathrm{D}=$ Items shared between the two systems.

$\mathrm{M}=$ Cases not reported [(S1-D)+(S2-D)+D]-n.

$$
\begin{gathered}
N=\frac{(S 1+1)(S 2+1)}{D+1}-1 \\
V=\frac{(S 1+1)(S 2+1)(S 1-D)(S 2-D)}{(D+1) 2(D 2+1)} \\
95 \% C I=N \pm 1.96 \sqrt{V}
\end{gathered}
$$

Hilealth in

Emergencies and Disasters [O]uarterly

Figure 1. Capture-recapture methods and its formula. 


\section{Results}

During the study period (2004-2009), Forensic Medicine System registered 3289 cases of death and Death Registration System, 3771 cases. After adjusting the variables, including full name, age, gender, and date of death, shared cases of 2 systems were calculated to be 2166 individuals and the multiplicative (sum of shared and non-shared cases in 2 systems) of 2 systems was 4894 . Using capture-recapture method formula, the total number of road traffic deaths in the province was estimated to be 5726 individuals (5818-5634:CI95\%). Based on the estimated figure, Forensic Medicine System and Death Registration System covered approximately 57.4\% and $65.8 \%$ of cases, respectively, and taken together, approxi-

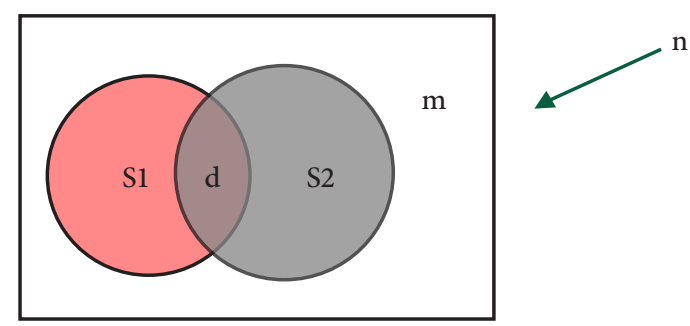

$$
\begin{aligned}
& \mathrm{S} 2=3289 \\
& \mathrm{~S} 1=3771 \\
& \mathrm{D}=2166 \\
& \mathrm{n}=[(1+3289)(1+3771) / 1+2166]-1=5726 \\
& \mathrm{M}=[(2166-3289)+(2166-3771)+2166]-5726=832
\end{aligned}
$$

\section{IHlealth in}

Emergencies and [D]isasters [Oluarterly

Figure 2. Capture-recapture method and its calculation formulas. mately $85.4 \%$ of mortalities. This means that about 832 individuals were missed (Figure 2).

According to Table 1, Death Registration System registered more road traffic deaths than Forensic Medicine Department, but the frequency of both systems had a significant difference with the estimated frequency obtained by capture-recapture method. This difference decreased gradually over 2004-2009.

According to Figure 3, the number of road traffic deaths over the study years in both registration systems, had no significant differences with each other, but there was a significant difference between this number and the number calculated based on capture-recapture method. The difference gradually declined during the final years of study.

In terms of recording demographic variables of the deceased (Table 2), both Death Registration System and Forensic Medicine Department had registered 2 variables of age and gender with a minor difference. Furthermore, in 2 systems more than two-thirds of the deceased were men and the majority of the age group of the deceased belonged to $15-34$ years (45\%) age range and the lowest percentage was related to children under 5 years $(1.1 \%)$.

\section{Discussion}

After using capture-recapture method for the first time in the province to better estimate the road traffic deaths, it was found that Death Registration System and Forensic Medicine Department had reported 65.8\% and 57.4\% cases of deaths, respectively. In fact, 2 systems underreported about $15 \%$ cases of deaths. According to the findings, death rate based on the information obtained from Death Registration and Forensic Medicine Department was less

Table 1. The absolute frequency of road traffic mortality based on data obtained in the forensic system, death registration system and capture-recapture methods in Kurdistan province during 2004-2009.

\begin{tabular}{ccccc}
\hline Year & Population & $\begin{array}{c}\text { Forensic medicine } \\
\text { department system }\end{array}$ & $\begin{array}{c}\text { Death registration } \\
\text { system }\end{array}$ & $\begin{array}{c}\text { Capture-recapture } \\
\text { method }\end{array}$ \\
\hline & $\begin{array}{c}\text { Estimated based on } \\
\text { 2006 census }\end{array}$ & Frequency & Frequency & Frequency \\
\hline 2004 & 1420858 & 449 & 493 & 854 \\
\hline 2005 & 1430507 & 606 & 650 & 1145 \\
\hline 2006 & 1440156 & 608 & 683 & 1110 \\
2007 & 1449805 & 523 & 622 & 891 \\
\hline 2008 & 1459454 & 572 & 688 & 928 \\
\hline
\end{tabular}




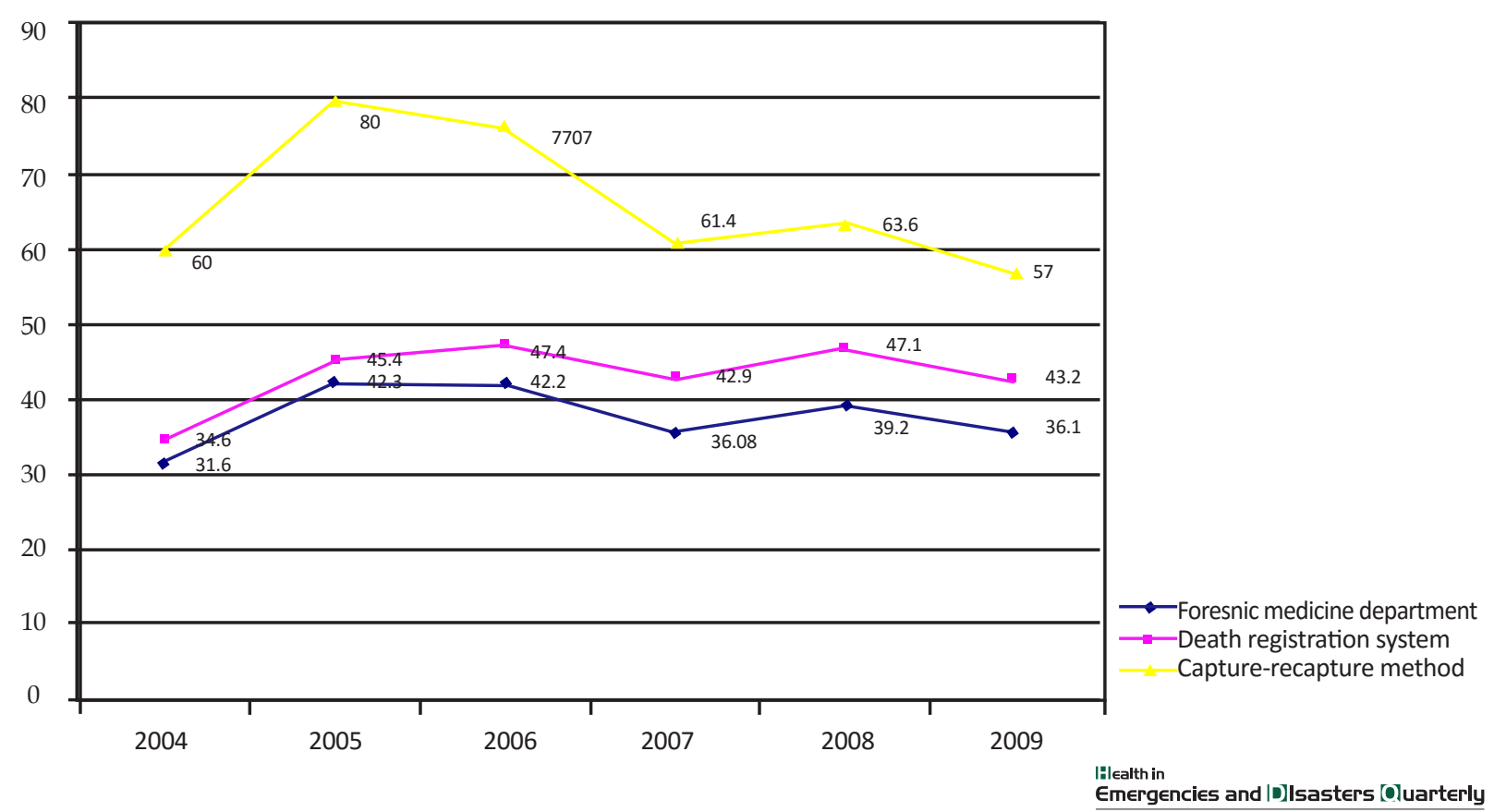

Figure 3. The percentage of thousand people road traffic mortality according to 2 registration systems of forensic medicine department and death registration and capture-recapture methods in Kurdistan province during 2004-2009.

than 50 per 100000 people, while estimation by capturerecapture method was more than 60 per 100000 people.

In Tercero et al. study in Nicaragua using capture-recapture method, $56.1 \%$ and $22.8 \%$ cases of road traffic deaths were reported from Police Department and hospi- tals, respectively and the percentage of under-reporting in 2 systems was 33\% [13]. In Razzak et al. study in Karachi, Pakistan who used this method, Police Department and hospitals reported $56 \%$ and $35.6 \%$ cases of death, respectively [9]. The current study showed that unlike 2 previous countries, registration systems of Kurdistan

Table 2. Frequency distribution of age and gender variables of the road traffic deaths according to the data obtained from forensic medicine department system and death registration system during 2004-2009.

\begin{tabular}{|c|c|c|c|c|c|}
\hline & & $\begin{array}{l}\text { Forensic medicine } \\
\text { department }\end{array}$ & Percentage & $\begin{array}{c}\text { Dead registration } \\
\text { system }\end{array}$ & Percentage \\
\hline \multirow{2}{*}{ Gender } & Male & 2645 & 80.4 & 3044 & 80.7 \\
\hline & Female & 644 & 19.6 & 727 & 19.3 \\
\hline \multicolumn{2}{|r|}{ Total } & 3289 & 100 & 3771 & 100 \\
\hline \multirow{9}{*}{ Age, $y$} & $<5$ & 34 & 3.4 & 42 & 1.11 \\
\hline & $5-14$ & 111 & 21.3 & 158 & 4.2 \\
\hline & $15-24$ & 702 & 24.08 & 848 & 22.5 \\
\hline & $25-34$ & 792 & 16.9 & 861 & 22.8 \\
\hline & $35-44$ & 555 & 12.5 & 613 & 16.3 \\
\hline & $65-54$ & 411 & 8.3 & 490 & 13 \\
\hline & $55-64$ & 273 & 12.4 & 291 & 7.7 \\
\hline & $\geq 65$ & 408 & 0.09 & 467 & 12.3 \\
\hline & Unknown & 3 & 0.09 & 1 & 0.02 \\
\hline Total & & 3289 & 100 & 3771 & 100 \\
\hline
\end{tabular}


through participation of relevant organizations have had more coverage. In 2002, in a review study in Kerman, Police, Forensic Medicine Department, and hospitals reported $16 \%, 58 \%$, and $48 \%$ cases of deaths, respectively [10]. In 2007, in another study in West Azerbaijan Province, the total number of road traffic deaths was estimated to be 1018 people. The method showed 121(87\%) under reported cases in both sources [11].

Under-reporting by Death Registration system could be due to under-reporting of deaths in the city. Health workers in rural areas report all deaths at the end of each month. However, in a city, there is a possibility of underreporting of cases due to large population. In this situation, coordination of Forensic Medicine Department, Registration, and Department of Transportation, and activation of health volunteers in the city, can reduce under-reporting to some extent.

Regarding forensic system, under-reporting may be due to the occurrence of deaths in villages and burying the deceased without reporting to Forensic Medicine Department. However, in the city, Forensic Medicine Department must issue a permit to bury the deceased. The under-reporting can be reduced in the system by using programs in health system, training of health workers, constant monitoring of the mortality data recording in the villages, and emphasizing on the authorization of the Forensic Medicine Department.

In terms of demographic characteristics, the distribution of deceased people based on gender in both systems was noticeable, so that the ratio of deceased male to female in the study population was 4.1. This proportion was similar to the figures found in the studies of Montazeri (19981999), Roudsari et al. (1998-1999) [20] in Tehran [21], and Rostami et al. (2000) in Ardebil [22], but it was less than the proportion found in the study of Khorasani et al. (2004) in Western Azerbaijan Province [11].

According to 2006 census, the relative distribution of population of men vs. women is $51 \%$ vs. $49 \%$. On the other hand, men have more outdoor activities, and hence more exposed to injuries compared to women. In addition, according to the cultural context of the community and the region under study, women tend to use smaller cars. Furthermore, we can say that more careful driving by women [11] and their compliance with driving rules has reduced their risk of death resulting from road traffic accidents.

Another important demographic finding of both systems was the age of the deceased. Most deceased people were in the age group of 15-34(45.3\%) years, who belonged to economically active age group. The reason can be due to more activity in this age group, or it might be because of the relative frequency of this age group (68.5\%) compared to other age groups, according to 2005 census. The findings of other studies, such as Montazeri [20], Mohammadi et al. in the city of Sirjan in Kerman Province during 2004-2009 [23], and Khorasani et al. in Western Azerbaijan Province [11], were similar to the present study.

\section{Conclusion}

Results of capture-recapture method showed that both systems had under-recording and capture-recapture method is a suitable method for accurate estimation of the number and rate of mortality. To reduce under-reporting, we suggest taking measures to correct registration system by recording national ID of the deceased in both systems and coordinate for exchanging information. Qualitative assessing of the reasons for under-registration of mortality data in Death Registration System and Forensic Medicine Department, developing intervention plans as amended effective factors, implementing research projects to increase coverage, improving the quality of registration, and reporting to Death Registration System and Forensic Medicine Department can help improve the accuracy of the registration system.

\section{Research limitations}

One of the research limitations was related to accessing the information of Forensic Medicine Department. Access to this information was hard due to the confidentiality of recorded information.

\section{Ethical considerations}

To conduct this study, organizational permission was obtained from the relevant authorities and we committed ourselves not to publish the study results anonymously. In addition, publishing intended information must be in coordination with the relevant organizations.

\section{Acknowledgements}

The article is extracted from Ms. Lida Gorgin's thesis in the department of epidemiology, faculty of medicine, Urmia University of Medical Sciences, Urmia, Iran.

\section{Conflict of Interests}

The authors declared no conflict of interests. 


\section{References}

[1] Jacobs GD, Sayer I. Road accidents in developing countries. Accidental Analysis \& Prevention. 1983; 15(5):337-53.

[2] Lyons R, Ward H, Brunt H. Using multiple datasets to understand trends in serious road traffic casualties. Accident Analysis and Prevention. 2008; 40(4):1406-410.

[3] Murray C, Lopez A, Mathers C, Stein C. The global burden of disease 2000 project: aims, methods, and data sources. Geneva: World Health Organization; 2001.

[4] Peden M, McGee K. Injury: a leading cause of the global burden of disease 2000. Geneva: World Health Organization 2002

[5] Peden M, Mohan D, Hyder A. World report on road traffic injury prevention. Geneva: World Health Organization; 2004.

[6] Mobalegi J, Maolanay N. [A survey of mortality caused by driving accidents in Sanandaj Besat hospital (Persian)]. Scientific Journal of Kurdistan University of Medical Sciences. 2001; 24(6):28-33.

[7] Mughisi A. [A guideline for cost-effectiveness calculation in safe communities (Persian)]. Tehran: Seda Publication; 2008

[8] Naghavi M, Jafari N, Alaeddin F, Akbari ME. [Injury epidemiology caused by external cause of injury in the Islamic Republic of Iran (Persian)]. Tehran: Baghe Rezvan; 2004.

[9] Razzak J, Luby S. Estimating mortality and injuries due to road traffic accidents in Karachi, Pakistan through the capture-recapture method. International Journal of Epidemiology. 1998; 27(5):866-70.

[10] Motavalian A, Holakoi K, Mahmodi M, Majdzadeh R. [Estimation of death due to road traffic injuries in Kerman district: application of capture-recapture method (Persian)]. Journal of the School of Public Health and Institute of Public Health Research. 2007; 5(2):61-72.

[11] Khorasani-Zavareh D, Mohammadi R, Laflamme L, Naghavi M, Zarei A, Haglund JA. Estimated road traffic mortality more accurately: use of the capture-recapture method in the West Azarbaijan Province of Iran. International Journal of Injury Control and Safety Promation. 2008; 15(1):9-17.

[12] Morrison A, Stone DH. Capture-recapture: a useful methodological tool for counting traffic relate injuries? Injury Prevention. 2000; 6(4):299-304.

[13] Tercero F, Andersson R. Measuring transport injuries in a developing country: an application of the capture-recapture method. Accident Analysis and Prevention. 2004; 36(1):13-20.

[14] Gill GV, Ismail A, Beching N. The use of capture- recapture techniques in determining the prevalence of type 2 diabetes. Monthly Journal of Association of Physicians. 2001; 94(7):34146.

[15] Schouten L, Straatman H, Kiemeney L. The capture-recapture method for estimation of cancer registry completeness: a useful tool? International Journal of Epidemiology. 1994; 23(6):1111-116.

[16] Robles S, Marrett L, Clarke E. An application of capture recapture methods to the estimation of the completeness of cancer registration. Journal of Clinical Epidemiology. 1988 41(5):495-501.
[17] Abeni D, Brancato G, Perucci C. Capture-recapture to estimate the size of the population with human immunodeficiency virus type 1 infection. Epidemiology. 1994; 5(4):410-14.

[18] Chiu W, Dearwater S, McCarthy D. Establishment of accurate incidence rates for head and spinal cord injuries in developed and developing countries: a capture-recapture approach. Trauma. 1993; 35(2):206-11.

[19] Dandona R, Kumar G, Ameer M. Under-reporting of road traffic injuries to the police: results from two data sources in urban India. Injury Prevention. 2008; 14(6):360-65.

[20] Montazeri A. Road-traffic-related mortality in Iran: a descriptive study. Public Health. 2004; 118(2):110-13.

[21] Roudsari B, Sharzei K, Zargar M. [Sex and age distribution in transport-related injuries in Tehran (Persian)]. Accident Analysis and Prevention. 2004; 36(3):391-98.

[22] Rostami K, Rezai-Sayad I, Zehori H. [Epidemiological driving accidents lead to death in Ardebil province (Persian)]. Journal of Ardabil University of Medical Sciences. 2008; $8(4): 381-86$

[23] Mohammadi G. Road traffic fatalities among pedestrians, bicyclists and motor vehicle occupants in Sirjan, Kerman, Iran. Chinese Journal of Traumatology. 2009; 12(4):200-202. 
